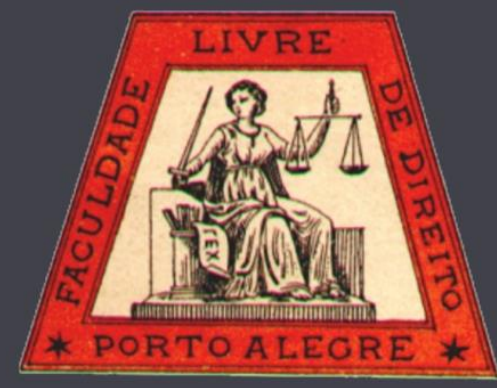

\title{
Contra a financeirização da economia e a mercantilização da sociedade
}

Against the financialization of the economy and the commodification of society

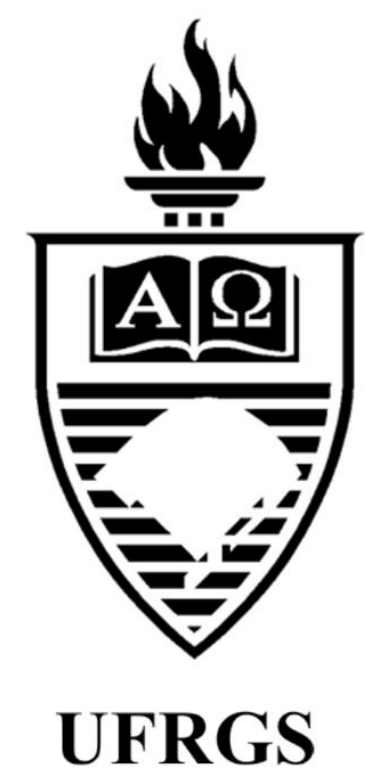

Jesús Ballesteros

Universitat de València

Revista da Faculdade de Direito da UFRGS

ISSN: 0104-6594 Site http://seer.ufrgs.br/revfacdir

Faculdade de Direito da UFRGS - Rua Riachuelo, 1317 - Centro - Porto Alegre - RS - Brasil

CEP - 90010-271 - Telefone: +55 5133083118 - Site http://www.ufrgs.br/direito/ 


\title{
Contra a financeirização da economia e a mercantilização da sociedade*
}

\author{
Against the financialization of the economy and the commodification of society
}

Contra la financiarización de la economía y la mercantilización de la sociedad

Jesús Ballesteros ${ }^{* *}$

\section{REFERÊNCIA}

BALLESTEROS, Jesús. Contra a financeirização da economia e a mercantilização da sociedade. Revista da Faculdade de Direito da UFRGS, Porto Alegre, n. 35, vol. esp., p. 32-49, dez. 2016.

\section{RESUMO}

A crise econômica do ano de 2007 tem duas dimensões. A primeira se refere à financeirização da economia que começa em 1971, quando o presidente Richard Nixon abandona o câmbio fixo do dólar pelo ouro e outorga livre circulação ao capital. A segunda é o triunfo da sociedade de mercado, ou seja, a hegemonia do capital como fator de produção e como valor social e econômico. Frente a estas duas dimensões, é necessário limitar os movimentos do capital e reconhecer os limites do dinheiro. Isto é, subordinar a economia ao direito para recuperar a responsabilidade e o compromisso com a realidade concreta.

\section{PALAVRAS-CHAVE}

Crise do Capitalismo. Economia ecológica. Enfoque das capacidades. Limites do Individualismo. Mercado. Socioeconomia.

\section{ABSTRACT}

The 2007 economic crisis has two dimensions. The first relates to the financialization of the economy beginning in 1971 when President Richard Nixon suspended the fixed relationship of the dollar to gold and granted the free floating exchange rate of capital. The second is the success of market society, that is, the hegemony of capital as a factor of production and as a social and economic value. Faced with these two dimensions, it is necessary to restrict capital movements and recognize the limits of money. That is, to subordinate the economy to law in order to recover responsibility and commitment to concrete reality.

\section{KEYWORDS}

Crisis of Capitalism. Ecological Economics. Capability Approach. Limits of Individualism. Market. Socioeconomics.

\section{RESUMEN}

La crisis económica del año 2007 tiene dos dimensiones. La primera se refiere a la financiarización de la economía que comienza en el año 1971 cuando el presidente Richard Nixon abandona el cambio fijo del dólar por el oro y otorga libre circulación al capital. La segunda es el triunfo de la sociedad de mercado, es decir, la hegemonía del capital como factor de producción y como valor social y económico. Frente a estas dos dimensiones es necesario limitar los movimientos del capital y reconocer los límites del dinero. Es decir, subordinar la economía al derecho para recuperar la responsabilidad y el compromiso con la realidad concreta.

\section{PALABRAS CLAVE}

Crisis del Capitalismo. Economía ecológica. Enfoque de las capacidades. Límites del Individualismo. Mercado.

Socioeconomía.

\section{SUMÁRIO}

Introdução. 1. Financeirização da economia: creditismo e bancocracia. 1.1. A criação de dinheiro do nada. 1.2. A irresponsabilidade dos representantes. 1.3. A União Europeia, exemplo de financeirização da economia. 2. Sociedade de mercado. 3. Recuperar os limites. 3.1. Limitar os movimentos do capital: frente à financeirização da economia. 3.2. Reconhecer as limitações do dinheiro: frente à sociedade de mercado. Referências.

\footnotetext{
* Texto original publicado em língua espanhola: BALLESTEROS, Jesús. Contra la financiarización de la economía y la mercantilización de la sociedad. Anuario da Facultade de Dereito da Universidade da Coruña, n. 17, p. 55-68, 2013. Disponível em: < http://ruc.udc.es/dspace/handle/2183/12534 >. Tradução de Marcos Pascotto Palermo (Mestre em Direito - PPGDir-UFRGS), com autorização do autor. Revisão da tradução por Alfredo de J. Flores (Professor Permanente - PPGDir-UFRGS). Agradece-se a colaboração de Luana da Silva Seeger (Mestranda em Direito pela UFSM).

** Catedrático de Filosofia do Direito e Filosofia política da Universitat de València (Espanha).
} 


\section{INTRODUÇÃO}

A crise de 2007 é uma crise múltipla (financeira, fiscal, monetária, econômica, moral e antropológica) e tem suas origens no niilismo, na perda do senso de realidade e dos sentidos, que deriva de uma economia que chega a ser designada como "autista". A crise na sua dimensão econômica tem duas vertentes diferentes, mas conectadas entre si. A primeira delas é a financeirização da economia, resultante da criação do "dinheiro do nada" mediante a especulação e o endividamento; e a segunda é a mercantilização da sociedade - a "sociedade de mercado", baseada precisamente na elevação desse dinheiro criado do nada à principal referência da sociedade.

\section{FINANCEIRIZAÇÃO DA ECONOMIA: CREDITISMO E BANCOCRACIA}

A financeirização da economia supõe a desproporção entre o tamanho das finanças e o da economia real, bem como a irresponsabilidade das primeiras. Este fenômeno conjugado surge nos anos 1970 com a dupla ruptura com o Bretton Woods ${ }^{\text {a: }}$ a) o fim da taxa de câmbio fixo do dólar no padrão-ouro, por decisão do presidente Richard Nixon em 1971; b) a livre circulação do capital, decidida por Giscard d'Estaing, Schmidt e Ford ${ }^{\mathrm{b}}$ em

\footnotetext{
${ }^{a}$ Nota de tradução: O sistema Bretton Woods resultou de acordos pactuados entre as nações ocidentais no ano de 1944 na "Conferência monetária e financeira da ONU" para regular a política econômica internacional e criar as instituições como o que será depois o Banco Mundial e o FMI.

b Nota de tradução: As citadas autoridades políticas da época implementaram um modelo que resultará depois no "neoliberalismo", principalmente na década de 1980 com os governos de Ronald Reagan nos EUA (Presidente entre 1981 e 1989) e de Margareth Thatcher na Grã-Bretanha
}

Rambouillet $^{\mathrm{c}}$, em 1975, dando origem à globalização econômica. Isso implicará na primazia total do capital por sobre os outros fatores produtivos e no domínio do dólar, qualificado com razão pelo General De Gaulle como privilégio exorbitante dos Estados Unidos. Ambas as rupturas põem fim ao período de maior estabilidade da economia de mercado nos últimos tempos, os que Jean Fourastié chamou de "trinta gloriosos" (1945-1975).

Assim, financeirização da economia implica dois aspectos: (1.1) a criação do "dinheiro do nada" e (1.2) o desmedido tamanho das finanças com a irresponsabilidade dos seus representantes.

\subsection{A criação de dinheiro do nada}

Em questão, a criação do dinheiro fiat $^{\mathrm{d}}$ pelos bancos centrais (emissão de moeda),

(Primeira-ministra entre 1979 e 1990), mas tendo elementos já uma década antes na França com Georges Pompidou (Presidente entre 1969 e 1974), o qual teria passado antes pelo Banco Rothschild.

c Nota de tradução: Nesta cidade francesa, em novembro de 1975, dá-se a formação do G6 mediante uma reunião convocada pelo então presidente francês, Valéry Giscard d'Estaing.

d Nota de tradução: a expressão dinheiro fiat ou moeda fiat (inspirado na expressão do latim, Fiat Lux, faça-se a luz) reflete uma expressão da língua espanhola para o que se traduziria por moeda fiduciária. Explica, todavia, Andrés Antheus que o dinheiro "fiat" (do latim "faça-se", como em "fiat lux"), ou por decreto, faz referência ao dinheiro cuja principal característica é o respaldo legal. Frequentemente se utiliza de forma intercambiável com dinheiro fiduciário, já que o dinheiro baseado em dívida geralmente coincide em ter, por sua vez, o respaldo legal. Porém, os termos não são equivalentes e a matiz pode ser considerável. O elemento essencial para que una moeda possa ser considerada "dinheiro fiat" é o seu uso obrigatório em uma jurisdição por imposição de uma lei de curso legal ou lei de curso forçoso (Ver: https://www.ellibrepensador.com/2014/05/06/el-

verdadero-valor-del-dinero-la-confianza/). O Banco Central Europeu o define como a moeda que é estabelecida pelos governos para centrar uma economia em um tipo de transação média, por exemplo, euro, dólar e iene (nesse sentido, pode-se ver: http://www.ecb.europa.eu/pub/pdf/other/virtualcurrencysc hemesen.pdf). 
bancos comerciais (derivados) e bancos de investimento (especulação).

A financeirização da economia começa a partir de 1968, quando se quebra a taxa fixa de câmbio do dólar vinculado ao ouro (US\$ 35 por onça) e se começa a expandir o crédito de modo ilimitado e incontrolável. Isto é feito por intermédio das seguintes instituições: (a) os bancos centrais, (b) os bancos comerciais e (c) o Shadow Banking.

a) Quanto aos bancos centrais, criam o dinheiro exógeno ou o dinheiro legal - moedas e cédulas da moeda de curso legal. É o único tipo de dinheiro de que falam a Escola Neoclássica e o monetarismo de Friedman.

$\mathrm{O}$ monetarismo leva à sua culminação a ideia neoclássica da exclusão da política e do Estado, que havia começado em Stanley Jevons ${ }^{1}$, com a eliminação da palavra "política" da designação da economia. A ideia seria deixar para a espontaneidade do mercado, já que este seria racional e perfeito, enquanto baseado no desejo. É o que defendem Fama ${ }^{2}$, Robert Lucas ou Alan Meltzer, seguindo a M. Friedman. A tese monetarista de Friedman ${ }^{3}$ de que o aumento proporcional e progressivo da oferta monetária contribui para o aumento da riqueza de uma nação supõe una reformulação mecanicista da velha teoria quantitativa do dinheiro ${ }^{4}$. A defesa

\footnotetext{
${ }^{1}$ Ver: JEVONS, Stanley. Teoría de la economía política. Madrid: Pirámide, 1998.

${ }^{2}$ Ver: FAMA, Eugene F. Efficient Capital Markets II. The Journal of Finance, v. 46, n. 5, p. 1575-1617, dez 1991.

${ }^{3}$ Ver: FRIEDMAN, Milton. The Optimum Quantity of Money and other Essays. London: Macmillan, 1969.

${ }^{4}$ Para a crítica a Friedman como visão mecanicista da teoria quantitativa do dinheiro, ver: HUERTA DE SOTO, J. Dinero, crédito bancario y ciclos económicos. Madrid: Unión Editorial, 1998. p. 407. Nesta mesma linha, R. Duncan criticou ao longo de toda a sua obra este impulso para a criação ilimitada de dinheiro como crédito/dívida, sem respaldo algum. Agora, em seu último livro: DUNCAN, R. The new Depression: The Breakdown of the Paper Money Economy. Singapore: John Wile \& Sons,
}

da criação de dinheiro por parte do Estado remonta a Knapp, defensor da tese cartalista $^{5}$, oposta à metalista e segundo a qual o dinheiro deve a sua realidade ao poder público e não ao seu valor intrínseco. O cartalismo contribui assim para a perda de valor objetivo do dinheiro como instrumento de câmbio e para a sua redução a dinheiro fictício, ao "dinheiro fiat". Esta tese terá sua manifestação histórica em 1971 com a decisão do Presidente Nixon, influenciada por Friedman, de desconectar o dólar do padrão-ouro ${ }^{6}$. Com isso, o Federal Reserve poderia recorrer à produção de dólares sem limite algum, não somente com a redução das taxas de juros ${ }^{7}$, mas acima de tudo com a criação de papel-moeda para além do ouro disponível. Friedman havia interpretado a crise de 1929 como resultante da restrição por parte do Federal Reserve System da emissão de moeda e do não-resgate de seus bancos. Assim, enquanto a massa de dólares tinha crescido apenas 55\% entre 1945 e 1965, no período de 1970-2001 cresceu $2.000 \%$. A dívida pública que era em 1971 de 436 bilhões, em 2005 excede a 8 trilhões ${ }^{8 \mathrm{e}}$; Ben Bernanke seguiu estes mesmos

2012 (especialmente, cap. 4 - "Creditopia" - e cap. 5 "The theory quantitative of credit").

5 À escola cartalista pertencem tanto Keynes como Friedman, enquanto que a Escola austríaca é metalista. Entretanto, Keynes considera prioritário lutar contra a greve e os rentistas - para isso, defende a pressão impositiva sobre as rendas mais altas, enquanto que Friedman considerava inevitável a greve e era contrário aos impostos.

${ }^{6}$ Sobre isso, remeto a meu artigo: BALLESTEROS, J. Globalization: from Chrematistic Rest to Humanist Wakefulness. In: BALLESTEROS, Jesús; FERNÁNDEZ RUIZ-GÁLVEZ, Encarnación; TALAVERA, Pedro (ed.). Globalization and Human rights: Challenges and Answers from a European Perspective. Dordrecht / Heidelberg / London / New York: Springer, 2012. p. 7 et seq.

${ }^{7}$ É a proposta de Friedman: FRIEDMAN, M. The Case for Flexible Exchange Rates. In: FRIEDMAN, M. Essays in Positive Economics. Chicago: University of Chicago Press, 1953.

${ }^{8}$ Ver: NADAL, A. Globalización financiera: las primeras 72 horas. México: La Jornada, 2012. 
slogans de Friedman com a sua política da quantitative easing ${ }^{\mathrm{f}}$. A criação de dinheiro sem economia, de "dinheiro fiat", será levada a cabo também pelas demais instituições financeiras.

b) Um passo a mais na consolidação da financeirização da economia consiste em abandonar o poder de criar dinheiro do nada nos Bancos comerciais mediante a redução ${ }^{9}$ do coeficiente de caixa a $1 \%$. O banco usurpa assim do Estado a sua soberania ${ }^{10}$ ao apropriar-se da produção de dinheiro, que deixa de ser moeda para converter-se em simples operações contábeis, em crédito/dívida. Deste modo, o monetarismo fica superado pelo creditismo ${ }^{11}$.

Para aumentar seus benefícios, a banca trata de converter o cidadão em simples consumidor, dependente, para todos os efeitos, de suas operações. Faz o cliente crer na total cobertura do risco por meio de um jogo de seguros, pretendendo fazer desnecessário o sentido de responsabilidade pessoal e de solidariedade familiar ou social. O cliente (quiçá fosse melhor dizer paciente...) viverá pendente de suas dívidas hipotecárias contraídas para conseguir empréstimos para a compra de vivendas e outros bens mais ou menos duráveis, bem como o será da tentativa de garantir um

\footnotetext{
e Nota de tradução: o texto está disponível no seguinte site: http://www.jornada.unam.mx/2007/04/11/index.php?sectio $\mathrm{n}=$ opinion\&article $=025 \mathrm{a} 1 \mathrm{eco}$

f Nota de tradução: refere-se à flexibilização quantitativa.

${ }^{9}$ A crítica a tal posicionamento pode ser encontrada em Huerta de Soto (HUERTA DE SOTO, J. Dinero, crédito bancario y ciclos económicos, cit.) e no IMF Working Paper (INTERNATIONAL MONETARY FUND. The Chicago Plan Revisited. IMF Working Paper (Research Department). Prepared by Jaromir Benes and Michael Kumhof; authorized for distribution by Douglas Laxton, August 2012, p. 17 et seq.), do qual falaremos no final deste artigo.

${ }^{10}$ Essa subordinação do Estado aos mercados financeiros corresponde ao modelo de F. Modigliani e M. Miller citado em: BRESSER-PEREIRA, L. C. The global financial crisis, neoclassical economics and neoliberal years of capitalism. Revue de la régulation, 18-06-2010.

${ }^{11}$ Sobre a crítica ao creditismo, ver o livro: DUNCAN, R. The new depression, cit. p. 57 et seq.
}

futuro pós-emprego com a especulação do mercado de ações de seu fundo de pensão. Os salários das classes média e baixa cairão pelo imperativo da competitividade, enquanto que pedir empréstimos hipotecários será uma operação de fácil acesso. O bem-estar ficará vinculado ao cartão de crédito. Conforme destacou Raghuran G. Rajan, no primeiro capítulo ("Que comam crédito") de seu livro intitulado "Rachaduras do sistema" 12 , a desigualdade aumentou nos Estados Unidos desde 1970, porque os mais pobres tiveram menor acesso à educação, ainda que tivessem maior acesso ao crédito.

\section{c) A banca na sombra (Shadow Banking).} Porém, a porcentagem das contas correntes com relação a totalidade da massa monetária tem se reduzido nos últimos anos. Com efeito, desde o final dos anos 1970, a mesma banca comercial, devido a sua desregulamentação, desnaturalizase acrescentando um novo elemento de criação de dinheiro com os derivados, produtos projetados por engenheiros que abandonaram a produção pelas finanças, e que tendem a fazer negociavéis de modo imediato os próprios créditos concedidos pelos Bancos. Os derivados são uma espécie de bônus que joga na bolsa. Com a sua venda, os Bancos comerciais se convertem e se confundem com os Bancos de investimento $^{13}$, fato que se legaliza com Clinton em 1999 com a revogação da lei Glass Steagall, que havia mantido a separação de ambos os tipos de Bancos. O volume dos derivados é algo sensivelmente colossal e esmagador. Segundo o Banco Mundial, os derivados somavam 684

\footnotetext{
12 Ver: RAJAN, Raghuran G. Grietas del sistema: ¿Por qué la economía mundial sigue amenazada?. Bilbao: Deusto, 2011.

${ }^{13}$ Ver: MINSKY, Hyman P. Securitization (1987). Preface and Afterword by L. Randall Wray. Policy Note 2008/2. The Levy Economics Institute of Bard College, p. 03. Ver também: LIAW, $\mathrm{K}$. Thomas. The business of the Investment Bank: a comprehensive overview. $3^{\text {rd }}$ ed. Hoboken, New Jersey: John Wiley \& Sons, 1999.
} 
trilhões de dólares, equivalente a 11 vezes o PIB mundial. Do mesmo modo, a proporção de ações da bolsa passou de ser 6,5 inferior em 1990 para ser 8 vezes maior em 2006. Estes derivados são negociados nos Over the Counter e, desse modo, produz-se a interconexão entre os bancos e os NBFI (Non-bank financial intermediaries ${ }^{g}$ ) ou Shadow Banking, a banca na sombra. Assim, os hedge funds, núcleo-duro do sistema bancário sombra, duplicam em volume de negócio ante o sistema bancário oficial ${ }^{14 h}$. Daí o enorme poder da ISDA (International Swaps and Derivatives Association) e sua influência sobre os Bancos Centrais. ${ }^{15}$

Os derivados, exemplo paradigmático do jogo do mercado de bolsas atual, claramente auto-referencial, assumirão a aposta no futuro de tudo: moeda estrangeira e ouro; sobre como subirão ou baixarão os produtos financeiros; e o que é ainda mais grave - matérias-primas e alimentos, e agora seguros de vida e títulos de alto risco ${ }^{\mathrm{i}}$ com nome diferente. $\mathrm{O}$ mais alarmante hoje é o aumento do preço dos matérias-primas alimentares, devido à acumulação de solo fértil, especialmente no continente africano. Colheitas inteiras são compradas por períodos de cinquenta ou mais anos, por parte da China e da Arábia Saudita, o que está causando um distúrbio na cotização internacional dos produtos básicos ${ }^{16}$.

\footnotetext{
g Nota de tradução: atualmente é mais comum encontrar NBFI com o uso de "Non-bank financial institutions", como se pode perceber da documentação do Banco Mundial.

14 Sobre isso, ver o cap. 5 do importante documento: FINANCIAL STABILITY REPORT. Global Shadow Banking Monitoring Report Global Shadow Banking Monitoring Report, 2012.

${ }^{\mathrm{h}}$ Nota de tradução: tal documento do Financial Stability

Report está disponível em: <http://www.fsb.org/wp-

content/uploads/r_121118c.pdf $>$.

${ }^{15}$ Quanto a isso, insistiu J. Stiglitz: STIGLITZ, J. Caída libre: El libre mercado y el hundimiento de la economía mundial. Madrid: Taurus, 2010.

'Nota de tradução: são os "junk bonds", como são chamados nos EUA os títulos de alto risco.

${ }^{16}$ Do antagonismo entre derivados e desenvolvimento
}

Em 16 de setembro de 2009, o Programa Alimentar Mundial das Nações Unidas alertou que o número de pessoas que passam fome atingiu um recorde histórico, ao superar os bilhões. Por outro lado, devemos ter em mente que, com menos de $1 \%$ do que os governos têm injetado no sistema financeiro para pagar os excessos jogo patológico em seus respectivos países, poderia estar resolvido o problema da fome ${ }^{17}$. No conjunto, a volatilidade constitui um ataque aos direitos humanos, porque incrementa a vulnerabilidade, a pobreza e a marginalização ${ }^{18}$. Daí a urgência da proibição da especulação sobre matérias-primas, alimentos e produtos energéticos, por meio de mecanismos públicos de estabilização de preços. Assim, aparece o que foi corretamente designado como capitalismo de cassino, rapidamente censurado por Peter Drucker e Susan Strange, que destacam o enorme risco que supõe a desproporção entre dinheiro em circulação e riqueza real. Ao cliente hipotecado, convence-se também que a melhor garantia para assegurar a terceira idade é tornarse titular de um fundo de pensões, de modo que acaba vendo que também a sua pensão entra no jogo de mercado de bolsa e pode contribuir para a falência da empresa em que trabalha. Deste modo, o nexo entre poupança e especulação produz efeitos tão nefastos que um autor tão

econômico se ocupa o livro: BREGER BUSH, Sasha. Derivatives and Development: A Political Economy of Global Finance, Farming and Poverty. New York: Palgrave MacMillan, 2012.

${ }^{17}$ Especialmente trágico é o caso de Somália - sobre tal tema: GARIBO, A. P. From the Errors of Colonialism to Horrors of War. In: BALLESTEROS. Globalization and Human Rights, cit. p. 113-141.

${ }^{18}$ Quanto a isso, igualmente: SCHUMACHER F. Small is beautiful: Economics as if people mattered. London: Blond and Briggs, 1973. p. 23 et seq. Já sobre a conexão entre volatilidade e vulnerabilidade, ver: GONZÁLEZ, J. I. La volatilidad acentúa la vulnerabilidad. Innovar: Revista de Ciencias Administrativas y Sociales, n. 021, Bogotá, Universidad Nacional de Colombia, p. 25-30, enero-junio 2003. 
sensato quanto Paul Dembinski ${ }^{19}$ afirma que o bom senso hoje exigiria o desmantelamento desses lugares de poupança que ameaçam a estabilidade da economia real.

A financeirização da economia faz parte falsa crença, constante na história económica, que consiste em ver como uma necessidade inevitável do progresso o desprezo aos setores econômicos dominantes anteriormente ${ }^{20}$. Assim, a sociedade industrial, baseando-se na transformação da natureza pelo trabalho, pretendeu desvalorizar o setor primário, que vivia do aproveitamento direto dos recursos da terra, tais como mineração, pesca, caça ou agricultura. Com o auge do setor de serviços, algo semelhante ocorreu em relação ao setor industrial. A financeirização da economia despreza de tal forma o sector secundário que leva a considerar os serviços financeiros como indústria (para a Grã-Bretanha, a City é a sua primeira "indústria"), esquecendo-se da distinção central que havia estabelecido Thorstein Veblen entre a autêntica indústria produtiva e os negócios, que seguem a rapinagem ${ }^{21}$. Na terceirização $^{j}$ da economia, o material de trabalho não é a terra ou a matéria, mas o próprio homem, o cliente, que, por sua vez, passa a ser manipulado pelo marketing. Esse predomínio do terceiro setor se baseia na suposta lei dos rendimentos crescentes, que, contudo, tem como consequência a emergência de monopólios ${ }^{22}$.

\footnotetext{
${ }^{19}$ Ver sobre isso: DEMBINSKI, Paul. Finanzas que sirven o finanzas que engañan. Madrid: Pirámide, 2010. p. 220 et seq.

20 Ver: CLARK, C. Las condiciones del progreso económico. Madrid: Alianza Editorial, 1980.

21 Conforme: VEBLEN, Thorstein. The Instinct of Workmanship and the Irksomeness of Labor. The American Journal of Sociology, v. 4, 1898-1899, p. 187201.

j Nota de tradução: utiliza-se aqui a expressão

"terceirização da economia" no sentido mais comum de "Service economy", correspondendo ao que se chama de "terciarización" em espanhol.

${ }^{22}$ Sobre o tema: COHEN, D. La prosperidad del mal: Una introducción (inquieta) a la economía. Madrid: Taurus,
}

\subsection{A irresponsabilidade dos representantes}

Ao tamanho excessivo das finanças se junta a irresponsabilidade de seus maiores representantes, de acordo com o princípio "too big to fail", introduzido por Alan Greenspan, presidente do FED (Federal Reserve) em 1987.

O desprezo pelos setores produtivos anteriores está ligado, por sua vez, ao entusiasmo pelo maior, pela economia de escala e pelo global. Assim, "as cooperativas de crédito queriam tornar-se bancos, os bancos comerciais em bancos de investimento, e estes em fundos especulativos, os hedge funds" 23 .

A tese de M. Friedman de não deixar cair os grandes bancos por considerá-los sistêmicos leva a Greenspan a colocar o FED a serviço de Wall Street a partir de 1987, provocando a irresponsabilidade dos grandes bancos ${ }^{24}$. Em 1998, repete-se esta submissão do FED à Wall Street com o resgate do hedge fund Long Term Capital Management, consolidando o sistema da banca privada na sombra. O princípio de "Too big to fail" ${ }^{25}$ não produziu somente a impunidade dos responsáveis pelo desastre, os grandes bancos de investimento, mas também a transferência da dívida dos bancos com os Estados, provocando a crise fiscal destes, com o risco de vários deles caírem em default, como foi o caso da Irlanda e Chipre, frente à atitude mais

2011. p. 222 - em que demonstrou seus limites nas crises das ".com".

${ }^{23}$ A esse entusiasmo pelo grande não era alheio o próprio Marx, devido a suas loas ao espírito burguês, na primeira parte do Manifesto Comunista, onde afirma que só os reacionários sentem falta da perda da indústria nacional.

${ }^{24}$ Sobre isso: ver: RAJAN, R. Grietas del sistema, cit.

25 Ver: ROUBINI, Nouriel; MIHM, Stephen. Crisis Economics: A crash course in the future of the finance. Londres: Penguin, 2010. p. 210 e 50. Na crítica à liberdade de movimento de capitais como principal causa da crise, insiste Orlean (ORLEAN, A. De l'euphorie à la panique: comment penser la crise financière. Paris: Ed. Rue d'Ulm, 2009. p. 93 e 100), afirmando que a busca de liquidez instantânea dos investidores é mais grave que a opacidade dos produtos financeiros. 
sensata adotada pela Islândia para responsabilizar os banqueiros responsáveis pela falência.

Simultaneamente se produz o protagonismo dos acionistas (shareholders value). Como proposto por Milton Friedman ${ }^{26}$ em 1970, a responsabilidade social da empresa se limita a ampliar o valor do acionista. Este, por sua vez, pode desmanchar a empresa, dissolvêla, vendê-la. Neoclassical value is shareholders value $^{27}$. O protagonista da atividade econômica deixa de ser o empreendedor que enfrenta os limites dos recursos a serem gerenciados, e passa a ser o homo financiarius, que atua em um mundo virtual de dinheiro fictício. Incentiva-se o risco aumentando a retribuições (bônus) dos operadores financeiros que arriscam mais, enquanto os salários dos trabalhadores são reduzidos ${ }^{28}$. De acordo com o ex-economistachefe do FMI, Simon Johnson, “de 1973 a 1985, o setor financeiro nunca ganhou mais que $16 \%$ dos benefícios empresariais nacionais, enquanto que, na década atual, chegou a $41 \%$. No que se refere às remunerações dos financeiros, a partir de 1983 , chegaram a atingir $181 \%$ de todas as indústrias privadas". O incremento do lucro promove a economia de escala, o princípio do "melhor é o quanto maior" 29 , sendo que concomitantemente reduz o tempo para o instantâneo. As corporações multinacionais que controlam $11 \%$ da produção mundial, mas representam $2 / 3$ do comércio mundial ${ }^{30}$, buscam

\footnotetext{
${ }^{26}$ Ver: FRIEDMAN, M. The Social Responsibility of Business is to Increase Its Profits. The New York Times Magazine, 13-09-1970.

27 Sobre isso: DEMBINSKI, P. ¿Finanzas que sirven $o$ finanzas que engañan?, cit. p. 156-165.

${ }^{28}$ Ver: BROWN, E. Web of Debt: The Shocking Truth about Our Money System and How We Can Break Free. Third Millennium Press, 2007.

${ }^{29}$ Ver: SCHUMACHER F. Small is beautiful, cit. $1 / 4$.

30 Ver: DEMBINSKI, P. H. ¿Finanzas que sirven o finanzas que engañan?, cit. cap. 6.
}

o maior rendimento de acionistas junto com o congelamento dos salários ${ }^{31}$.

\subsection{A União Europeia, exemplo de financeirização da economia}

Apesar de sua origem anglo-saxônica, esta financeirização da economia também passa para a União Europeia com o Tratado de Maastricht, no qual abandona o projeto inicial da união política europeia em favor do simples projeto da união monetária. Os dirigentes europeus na época - Kohl, Mitterrand, Major, Andreotti ou González - foram seduzidos pelas propostas da European Round Table of Industrials (ERT), fundada em 1983 pelas principais multinacionais europeias ${ }^{32}$ e deixaram os Estados à mercê dos bancos e mercados financeiros.

A perda de soberania monetária estabelecida em Maastricht implicará na submissão dos Estados aos bancos de várias maneiras:

a) atribuindo aos bancos privados a criação de dinheiro mediante empréstimos, e ao Banco Central, também de capital privado, o direito de imprimir cédulas;

b) proibindo em seu artigo 104 os Estados de receber financiamento direto do Banco Central, forçando-os a pagar juros mais elevados, em média 4\%, dependendo dos CDS (Credit Default Swaps), sofrendo riscos para colocar os seus títulos nos bancos, apesar de terem recebido do Banco Central o interesse de 0'75;

\footnotetext{
${ }^{31}$ Ver: BLOND, P. Red Tory: How Left and Right Have Broken Britain and How We Can Fix It. Londres: Faber, 2010.

${ }^{32}$ Em outras, as britânicas Shell e Imperial Chemiques Industries; a italiana Fiat; a suiça Nestlé; a alemã Dammler Benz; as espanholas Telefónica e Repsol, assim como os principais bancos europeus. Seu principal impulsor, o visconde Etienne Davignon, foi presidente do Club Bilderberg (1999-2011).
} 
c) impondo a abertura total das contas para o capital estrangeiro, rompendo com as regras mais prudentes do Tratado de Roma de $1957^{33}$ e impedindo o controle do capital volátil.

A má gestão das entidades financeiras convertidas em chave do sistema - levará a vulnerar as regras mais elementares da economia de mercado, com o princípio "too big to fail", o qual implica na negação da igual responsabilidade dos agentes econômicos, já que supõe a impunidade dos responsáveis pelo desastre, os grandes bancos de investimento. A assunção da dívida financeira por parte dos Estados levará ao risco de falência para estes e sua necessidade de resgate, provocando inicialmente danos para o contribuinte e, finalmente, a dissolução do Estado Social de Direito $^{34}$, salvo nos casos exemplares como a Islândia, que se recusou a perder a sua soberania.

A financeirização da economia conduz à mercantilização da sociedade, em que tudo está subordinado aos mercados, incluindo a dignidade humana. As relações humanas se reduzem a simples transações, negando-se todo princípio inegociável e todo direito inalienável.

\section{SOCIEDADE DE MERCADO}

A sociedade de mercado supõe a hegemonia do capital como fator de produção e como valor social e econômico. Em ambos os casos, esta é uma consequência dos postulados da economia neoclássica ou mainstream

\footnotetext{
${ }^{33}$ Sobre a infidelidade da União Europeia a suas propostas fundacionais, ver: DI TARANTO, G. L'Europa tradita: Dall'economia di mercato all'economia del profitto. In: CAPRIGIONE, F. (ed.). La nuova disciplina della società europea. Padova: Cedam, 2008.

${ }^{34}$ Ver: MOFFA, Claudio. Stato sociale, crisi finanziaria, sovranità nazionale: il nodo della Banca centrale Europea. In: GARGULlO, P.; CICARELlI, A. (org.). La dimensione sociale dell'Unione Europea alla prova della crisis globale. Milão: Franco Agnelli, 2012.
}

economic $^{35}$.

a) A hegemonia do capital como fator de produção é devido à crença na possibilidade de substituição completa da terra e do trabalho pela técnica, produto para transformar o capital. Assim, escreve Walras: "vemos que as terras, as pessoas e os bens de capital constituem o capital" ${ }^{\prime \prime}$.

b) A valoração do dinheiro como um valor supremo advém da elevação do desejo abstrato a motor básico do comportamento humano. Já em 1851, Arthur Schopenhauer disse: "O dinheiro é a felicidade humana $\mathrm{em}$ abstrato, porque ele não é capaz de apreciá-la de forma concreta; dedica-se com todo o seu coração à felicidade em abstrato" 37 . O desejo de possuir dinheiro enquanto possibilidade e disponibilidade abstrata desloca o afã de possuir bens concretos. Este espírito de abstração, criticado com agudeza por G. Simmel $^{38}$ e G. Marcel $^{39}$ como reflexo da primazia do dinheiro, desloca-se, por sua vez, do âmbito dos recursos materiais para o âmbito das relações afetivas, e acaba dissolvendo a distância presente ainda em Freud entre a necessidade e o desejo ${ }^{40}$, entre o princípio de realidade e o princípio de prazer, entre "ego" e "id", entre razão e impulso. A esquerda freudiana (Focault, Deleuze e Guattari) continua desenvolvendo essa disponibilidade

${ }^{35}$ Da Escola neoclássica e seus críticos atuais, ocupo-me no artigo: BALLESTEROS, J. La Escuela neoclásica: valores y derechos. Cuadernos electrónicos de Filosofía del derecho, 2012.

${ }^{36}$ Ver: WALRAS, Léon. Elementos de economía política pura. Madrid: Alianza, 1987. p. 373 et seq.

37 Ver ainda: SCHOPENHAUER, Arthur. Parerga $y$ paralipomena: Escritos filosóficos sobre diversos temas. Madrid: Trotta, 2006.

38 Nesse sentido, ver: SIMMEL, Georg. Filosofía del Dinero. Granada: Comares, 2003.

39 Ver: MARCEL, Gabriel. Etre et avoir. Paris: Aubier, 1935.

${ }^{40}$ Sobre isso: FERIA JALDON, E. Crítica de la razón tecnológica. Huelva: Diputación Provincial de Huelva, 1984. p. XI, 98 et seq. 
abstrata e ilimitada para o desejo, central nos escritos de André Gide ${ }^{41}$ e de seu tio, o economista neoclássico Charles Gide ${ }^{42}$, e inverte o sentido da obra de Freud defendendo o número indefinido de sexos e negando a regra do ouro base da ética em todas as grandes religiões universais - para dissolver a unidade de pessoa, afirmando que somos vários, dividuos, mais que indivíduos e, portanto, não podemos nos ocupar com terceiros, já que estamos suficientemente ocupados em atender nossos diferentes "eus". Esta aproximação é comum também na nova esquerda que retorna a confusão entre necessidade e desejo presente em $\operatorname{Marx}^{43}$ e permanece ancorada na primeira parte do Manifesto comunista acerca da contribuição positiva do capitalismo em favor da dissolução da religião, família, autoridade, tradição e por sua opção pelo grande e global.

A economia neoclássica postula ter como único ponto de referência o valor de troca, com abstração da perspectiva da justiça. $\mathrm{O}$ dinheiro aparece como um sinal de reconhecimento e valor, perdendo toda referência à realidade. O significante remete a outros significantes, sem que nunca se vislumbre algum significado ${ }^{44}$. Assim, dissolve-se o problema do valor no problema do preço, e se pode falar até mesmo do preço das pessoas ${ }^{45}$. Perde-se, portanto, o "tratar o outro como a si mesmo", e aumenta o número dos descartáveis socialmente quando aparecem em oposição às fantasias fantasmagóricas de

\footnotetext{
${ }^{41}$ Especialmente a partir de seu livro: GIDE, André. Los alimentos terrestres. Madrid: Alianza Editorial, 1980.

${ }^{42}$ Em seu artigo de 1915, O materialismo e a economia política, em que defende o desejo frente ao trabalho. Sobre os mesmos, chama a atenção com agudeza J. J. Goux en seu livro: GOUX, J. J. La frivolitè de la valeur. Paris: Blusson, 2000.

${ }^{43}$ FERIA JALDON, Crítica, cit. p. 19 et seq.

44 " $\mathrm{Na}$ era da economia financeira, do signo bancário, da moeda não conversível, a pintura se faz não referencial e seu preço se torna altamente especulativo" (GOUX, J. J. $L$ 'art et l'argent: La rupture moderniste, 1860-1920. Paris: Blusson, 2011. p. 98).

${ }^{45}$ WALRAS, L. Tratado de economía política pura, cit. p.
} 374. desejo. O que não é um objeto de desejo torna-se algo descartável, literalmente "indesejável"46.

\section{RECUPERAR OS LIMITES}

\subsection{Limitar os movimentos de capital: frente à financeirização da economia}

Há um consenso no sentido de que a financeirização da economia destrói a economia de mercado (a qual exige responsabilidade e competência), ao mesmo tempo que consolida a sociedade de mercado, o que eleva o dinheiro para o topo da pirâmide social. Portanto, é essencial acabar com os falsos juízos que a tornaram possível.

É necessário recuperar o espírito de ordoliberalismo $\mathrm{k}^{\mathrm{k}}$, segundo o qual "a economia de mercado só pode ocorrer em uma sociedade nãomercantilizada", já que as virtudes sociais - tais como trabalho, responsabilidade, sobriedade, solidariedade - que ela comporta são imprescindíveis. E com ela a subordinação da economia ao direito, regulando e controlando as finanças, tanto nos seus instrumentos mais tenebrosos - como CDS sem cobertura -, quanto nas entidades mais especulativas - os hedge funds e os tax haven, etc.

Para superar a financeirização da economia, é necessário superar o fetichismo da economia de escala, do "quanto maior, melhor", que leva ao desprezo para com o pequeno, bem como à devastação ecológica e social e ao monopólio. O capitalismo e sua projeção na globalização se caracterizam por esse "colossalismo" frente à economia de mercado, que está organizada à competição. Este colossalismo é a consequência da crença

\footnotetext{
${ }^{46}$ Sobre isso: BAUMAN, Z. Wasted lives: Modernity and its outcasts. Cambridge: Polity Press, 2003.

k Nota de tradução: o ordoliberalismo é a doutrina atrelada à política econômica da Alemanha do Pós-guerra, que era uma economia social de mercado que propõe a intervenção estatal no mercado.
} 
cientificista na superioridade do visual sobre o oral, do quantitativo sobre o qualitativo, das matemáticas sobre a experiência humana. A concentração dos capitais está ligada à dispersão mental, à falta de vida interior e de espírito crítico. Como escreve Röpke: "O capitalismo é oposto à economia de mercado, porque esta exclui os monopólios e oligopólios e exige pequenos agentes econômicos, enquanto que o capitalismo se apoia sobre aqueles e transfere para o possuidor do capital ingressos sem prestação própria". ${ }^{47}$ Deve-se recuperar o tamanho humano na empresa e no crédito para restabelecer a concorrência e reduzir as desigualdades $^{48}$, frente à situação atual em que os gerentes dos grandes bancos multiplicam os seus benefícios, enquanto o desemprego aumenta, devido ao fato de que a pequena e média empresa, que gera $90 \%$ do emprego, não tem crédito. O melhor banco é o banco de pequeno porte. Por essa via iria a (fracassada) reforma de Paul Volcker, assim como a tese de Dani Rodrik. Também no comércio é absurdo querer consumir produtos dos países mais remotos, em vez de defender a pequena indústria e o artesanato. A qualidade está relacionada com a pequena, com o artesanal.

Deve-se frear a especulação contra a dívida soberana e outros bônus que se realiza com operações a curto prazo e tão fraudulentas como as de apostar contra o não-pagamento da dívida com os Credits Default swaps, sem

\footnotetext{
47 Ver: RÖPKE, Wilhelm. Civitas Humana: Cuestiones fundamentales en la reforma de la sociedad y de la economía. Madrid: Revista de Occidente, 1949. p. 27.

${ }^{48}$ Como escreve Röpke (ibidem, p. 5): "Feudalismo y monopolio están implicados recíprocamente". A primazia do pequeno e do longo prazo implica o rechaço da Bolsa como eixe da economia. De sua parte, a Banca é concebida como financiadora da empresa e a empresa se baseia, por sua vez, na participação dos trabalhadores. A reforma do sistema financeiro, proposta por Paul Volcker, vai nesta mesma linha ordoliberal ao querer acabar com os Bancos demasiado grandes para cair, dividindo os Bancos, mas finalmente a Lei Dodd-Frank de 11-07-2010 foi mais modesta em suas exigências.
}

adquirir simultaneamente dívida. Existe uma diretiva europeia adotada nesta linha, aprovada em outubro de 2011, que deveria ter entrado em vigor logo.

O ganhador do Prêmio Nobel de Economia, o francês Maurice Allais (19112010), lucidamente criticou a subordinação dos Estados aos mercados financeiros, perguntando com humor quais eram esses mercados, e respondendo com a sua lista segundo o Departamento do Tesouro norte-americano: "J. P. Morgan, Bank of America, Citybank, Goldman Sachs, HSBC, Deutsche Bank, UBS, Credit Suisse, City Corp-Merril Lynch e BNPParibas"49. Allais viu na globalização financeira a principal responsável pela extensão do desemprego na União Europeia.

Nessa mesma linha, Dani Rodrik ${ }^{50}$ afirma que vivemos com a globalização em um verdadeiro trilema. Não é possível continuar com a globalização financeira, se quisermos manter a democracia e o Estado social. Seguindo a Keynes, considera que fomos longe demais com a globalização financeira e é necessário recuperar o sistema Bretton Woods para frear os capitais voláteis, que foram responsáveis pela crise asiática de 1997 e, em geral, por todas as crises econômicas. A hegemonia do capital, quando este se torna autorreferencial, deixou de responder ao que constitui o seu sentido - servir à economia produtiva - e, com isso, colocou em perigo as condições de dignidade de vida de milhões de pessoas. Por isso, deve ser regulado de acordo com os critérios de transparência e responsabilidade, para voltar a servir à economia produtiva, e esta, por sua vez, a todos os seres humanos.

49 Ver: ALLAIS, Maurice. La Mondialisation, la destruction des emplois et de la croissance, l'évidence empirique. Paris: Clément Juglar, 2007; ALLAIS, Maurice. La crise mondiale d'aujourd'hui: Pour de profondes réformes des institutions financières et monétaires. Paris: Clément Juglar, 1999.

50 Ver: RODRIK, Dani. The Globalization Paradox. London - New York: Norton and Co., 2011. 
O primeiro objetivo da economia deve ser o pleno emprego. Para isso, é preciso fomentar a produção industrial e o comércio, limitando a "economia de cassino". Isso requer policy space, "espaço político" para dirigir as políticas monetárias e fiscais, impondo a taxa Tobin sobre as transações financeiras. ${ }^{51}$

Há razões para confiar na recuperação do controle das finanças par parte do direito. O ímpeto da desregulamentação da Escola Neoclássica constitui uma exceção dentro da história econômica. Ocupa apenas algumas décadas de 1870 a 1929 e de 1970 até o presente. E chegou o momento de superá-lo.

O fato de que todos os países do mundo que tiveram uma melhora nos últimos tempos começando por Malásia -, como China, Índia, Brasil, Turquia, África do Sul, México, Coreia do Sul, têm controlado a conta de capital ao saber beneficiar-se da globalização financeira, subordinando-a ao bem comum nacional. Da mesma forma, os países que mais sofreram com a crise foram os tradicionalmente contrários a qualquer regulação das finanças como a GrãBretanha e os Estados Unidos.

Em um relatório de sua equipe, em fevereiro 2010 ${ }^{521}$, o FMI criticou a liberdade de movimentos de capitais e acabou apoiando a Islândia no seu não-pagamento aos bancos, devido à volatilidade das finanças depois da quebra do sistema Bretton Woods; ou seja, entre 1970 e 2008, ocorreram 124 crises bancárias, 208 crises monetárias e 63 crises da dívida soberana.

E em outro importante relatório, de agosto de 2012, preparado por Jaromir Benes e

\footnotetext{
${ }^{51}$ Dani Rodrik e Joseph Stiglitz, junto ao colombiano José Antonio Ocampo, são os editores da importante revista on line neokeynesiana "Journal of Globalization and Development", aparecida em 2010.

${ }^{52}$ OSTRY, Jonathan D. et alii. Capital Inflow: The Rol of Controls. In: IMF Staff Position Note. 19-02-2010.

' Nota de tradução: o texto está disponível em: < http://www.imf.org/external/pubs/ft/spn/2010/spn1004.pdf $>$.
}

Michael Kumhof, intitulado "The Chicago Plan Revisited", propõe recuperar a proposta dos autores como Von Mises (1912), Henry Simons (1933) e Irving Fisher (1933), Hayek (1937) e Rothbard (1983), Maurice Allais (1946) e Tobin $(1985)^{53}$, que consiste exigir dos bancos uma reserva (reserve banking) de $100 \%$ dos depósitos, o que acabaria com o nefasto princípio do "too big to fail", não podendo justificar-se com a defesa dos depositantes (previamente assegurada) e permitindo a igualdade de responsabilidade dos agentes econômicos, começando pela igualdade perante a quebra ${ }^{54}$. Ao mesmo tempo, postula a necessidade de recuperação da soberania monetária, do poder do povo para a emissão de moeda, que foi evaporado ao ceder à banca.

Como destaca Rawi Abdelal ${ }^{55}$, o Tratado de Roma de 1957 considera que o fundamental da União era a reconciliação, a paz e a união política, e tratava os fluxos de capitais como cidadãos de segunda categoria. Com essa visão de subordinação da economia, e mais ainda a das finanças, à política, a UE manteve rígidos os movimentos de capital até os anos 1980, o que corresponde ao seu período de maior prosperidade, os já lembrados "30 gloriosos".

Um ingrediente importante na necessária subordinação das finanças ao direito se constitui na taxa Tobin, como medida de luta contra a especulação, que agora se quer impor em 11 países da EU, com total oposição da GrãBretanha. É importante para reduzir a volatilidade.

Outros motivos para a esperança se encontram nos importantes passos dados contra a fraude fiscal, levadas a cabo pelo Consórcio Internacional de Jornalistas Investigativos

${ }^{53}$ HUERTA DE SOTO, J. Dinero, crédito bancario $y$ ciclos económicos, cit.

54 Ver: INTERNATIONAL MONETARY FUND. The Chicago Plan Revisited, cit., p. 17 et seq.

${ }^{55}$ Ver: ABDELAL, Rawi. Capital rules. The Construction of the global Finance. Cambridge, Massachussets: Harvard University Press, 2009. p. 156. 
(ICIJ $)^{56}$, com jornais como o Washington Post, The Guardian, Le Monde ou El confidencial; bem como a valiosa pesquisa realizada na Suíça pelo profissional de computação Hervé Falciani ${ }^{57}$ dentro do banco britânico HSBC. A sentença do Tribunal da EFTA, deu razão à Islândia ante a Grã-Bretanha e Holanda.

\subsection{Reconhecer as limitações do dinheiro: frente à sociedade de mercado}

A crença neoclássica na possibilidade de substituição completa da natureza e do trabalho pela técnica, juntamente com a crença na abundância ilimitada dos recursos naturais, encontra-se com o duplo limite da não-renovação dos recursos naturais e da não-reciclagem dos resíduos. Esta é uma das teses fundamentais da Economia ecológica, que recupera a tese fisiocrata do valor da natureza como um valor prioritário. Como muito bem afirmou Hinterberger ${ }^{58 \mathrm{~m}}$, “deveríamos ser cautelosos ao usar o termo 'capital' para o meio ambiente, porque, em teoria econômica, capital significa um fundo de dinheiro que pode circular, ou estoque de bens reprodutíveis - e nenhuma dessas propriedades se enquadra com o meio ambiente". Ante a "tragédia dos bens comuns"

${ }_{57}^{56}$ Ver: $\frac{\text { http://www.icij.org/offshore }}{\text { Ver: }}$ http://www.gebruederbeetz.de/en/productions/falcianis-list-at

${ }^{58}$ HINTERBERGER, Friedrich; LUKS, Fred; SCHMIDTBLEEK, Friedrich. Material flows vs natural capital: What makes an economy sustainable. Ecological Economics, 23, 1997 apud QUIROGA MARTINEZ, R. Participación, supresión de la pobreza y desarrollo sustentable. Santiago de Chile: FOSIS / FDLA, 2000.

m Nota de tradução: O mencionado texto de Friedrich Hinterberger está disponível agora no seguinte site: $<$ https://www.researchgate.net/publication/222477417_Ma terial_flows_vs_natural_capital'_What_makes_an_econom y_sustainable>.

${ }_{59}$ Conforme: HARDIN, G. The tragedy of commons. Science, $13 \mathrm{dez}$ 1968. Sobre isso, insistiram aparte dos autores partidários da economia ecológica: JONAS, Hans. El principio de responsabilidad: ensayo de una ética para la civilización tecnológica. Barcelona, Herder, 1995; OST, François. Naturaleza y derecho. Bilbao: Mensajero, 1996; fez-se urgente a consciência ecológica ante o individualismo metodológico ${ }^{60}$, para não cair em um biologismo grosseiro, tal como o proposto pela Deep Ecology ${ }^{61}$, buscando recuperar o sentido de responsabilidade de todos os habitantes do planeta Terra, tanto os presentes quanto os futuros.

É necessário que a economia supere as abordagens neoclássicas e sua pretensão de reduzir o conhecimento à análise quantitativamatemática, e recuperar a dimensão do qualitativa e, com isso, a consciência de pertencer ao âmbito das ciências sociais e, mais particularmente, ao campo da ética e da filosofia prática, subordinando-se à política ${ }^{62}$.

É necessário, também, corrigir o sentido da noção de disponibilidade ante a Escola neoclássica; e o instantaneísmo gideano já não deve ser tratado como uma abstração e falta de compromisso com a realidade concreta; pelo contrário, deve conectar com a ideia clássica da pobreza como máxima atenção às limitações e possibilidades da realidade concreta.

Da mesma forma, deve-se revisar o conceito neoclássico do capital humano, tal como fez a Escola das capacidades capitaneada por Amartya Sen ${ }^{63}$, bem como a socioeconomia,

SCREPANTI, E.; ZAMAGNI, Stefano. Panorama de historia del pensamiento económico. Barcelona: Ariel, 1997. p. 376 et seq.; ZAMAGNI, Stefano. Dalla teoria del valore utilità alla teoria del valore scelta: le dificoltà della posizione soggettivista in economia politica. Teoria politica, p. 53-67, 1987; ZAMAGNI, S. Marginalismo. In: Enciclopedia delle Scienze sociale. Trecanni, 1996, ap. 2; BRUNI, L. Le nuove virtù del mercato nell'era dei beni comune. Roma: Cittá Nuova, 2012. p. 73 et seq.

60 BALleSteros, J. Postmodernidad: decadencia o resistencia. $2^{\mathrm{a}}$ ed. Madrid: Tecnos, 2000. p. 29 e 152.

${ }^{61}$ Ver o cap. 1 da obra: BALLESTEROS, J. Ecologismo personalista: Cuidar la naturaleza, cuidar al hombre. Madrid: Tecnos, 1995.

${ }^{62}$ A ausência de política foi uma das causas primordiais da atual crise. Refiro-me naturalmente à política entendida no modo de pensar clássico, como responsabilidade pelo bem comum, não ao parasitismo político. Sobre isso, faço referência ao livro coletivo: BALLESTEROS, J. Globalization and Human Rights, cit. passim.

${ }^{63}$ Ver: SEN, Amartya. Sobre ética y economía. Madrid: Alianza, 1989. p. 91 et seq. Ver também: SEN, Amartya. 
com Amitai Etzioni ${ }^{64}$ e outros, ao estabelecer que o mais importante não é a disponibilidade de dinheiro, mas antes a capacidade humana de fazer o seu caminho na vida, o que exige muito mais do que simplesmente o capital humano, exigirá vontade de participação e projeto de vida.

La idea de justicia. Madrid: Taurus, 2009. p. 261-278 e 325-328.

${ }^{64}$ Ver: ETZIONI, Amitai. The Bankruptcy of liberalism and conservatism. Political Science Quarterly, v. 128, issue 1, p. 39-66, Spring 2013. 


\section{REFERÊNCIAS}

ABDELAL, Rawi. Capital rules. The Construction of the global Finance. Cambridge, Massachussets: Harvard University Press, 2009.

ALLAIS, Maurice. La crise mondiale d'aujourd'hui: Pour de profondes réformes des institutions financières et monétaires. Paris: Clément Juglar, 1999.

ALLAIS, Maurice. La Mondialisation, la destruction des emplois et de la croissance, l'évidence empirique. Paris: Clément Juglar, 2007.

BALLESTEROS, Jesús. Ecologismo personalista: Cuidar la naturaleza, cuidar al hombre. Madrid: Tecnos, 1995.

BALLESTEROS, Jesús. Globalization: from Chrematistic Rest to Humanist Wakefulness. In: BALLESTEROS, Jesús; FERNÁNDEZ RUIZ-GÁLVEZ, Encarnación; TALAVERA, Pedro (ed.). Globalization and Human rights: Challenges and Answers from a European Perspective. Dordrecht / Heidelberg / London / New York: Springer, 2012.

BALLESTEROS, Jesús. La Escuela neoclásica: valores y derechos. Cuadernos electrónicos de Filosofía del derecho, 2012.

BALLESTEROS, Jesús. Postmodernidad: decadencia o resistencia. $2^{\mathrm{a}}$ ed. Madrid: Tecnos, 2000.

BAUMAN, Z. Wasted lives: Modernity and its outcasts. Cambridge: Polity Press, 2003.

BLOND, P. Red Tory: How Left and Right Have Broken Britain and How We Can Fix It. Londres: Faber, 2010.

BREGER BUSH, Sasha. Derivatives and Development: A Political Economy of Global Finance, Farming and Poverty. New York: Palgrave MacMillan, 2012.

BRESSER-PEREIRA, L. C. The global financial crisis, neoclassical economics and neoliberal years of capitalism. Revue de la régulation, 18-06-2010.

BROWN, E. Web of Debt: The Shocking Truth about Our Money System and How We Can Break Free. Third Millennium Press, 2007.

BRUNI, L. Le nuove virtù del mercato nell'era dei beni comune. Roma: Cittá Nuova, 2012.

CLARK, C. Las condiciones del progreso económico. Madrid: Alianza Editorial, 1980.

COHEN, D. La prosperidad del mal: Una introducción (inquieta) a la economía. Madrid: Taurus, 2011.

DEMBINSKI, Paul. Finanzas que sirven o finanzas que engañan. Madrid: Pirámide, 2010. 
DI TARANTO, G. L'Europa tradita: Dall'economia di mercato all'economia del profitto. In: CAPRIGIONE, F. (ed.). La nuova disciplina della società europea. Padova: Cedam, 2008.

DUNCAN, R. The new Depression: The Breakdown of the Paper Money Economy. Singapore: John Wile \& Sons, 2012.

ETZIONI, Amitai. The Bankruptcy of liberalism and conservatism. Political Science Quarterly, v. 128, issue 1, , p. 39-66, Spring 2013.

FAMA, Eugene F. Efficient Capital Markets II. The Journal of Finance, v. 46, n. 5, p. 1575-1617, dez 1991.

FERIA JALDON, E. Crítica de la razón tecnológica. Huelva: Diputación Provincial de Huelva, 1984.

FINANCIAL STABILITY REPORT. Global Shadow Banking Monitoring Report Global Shadow Banking Monitoring Report, 2012.

FRIEDMAN, Milton. The Case for Flexible Exchange Rates. In: FRIEDMAN, M. Essays in Positive Economics. Chicago: University of Chicago Press, 1953.

FRIEDMAN, Milton. The Optimum Quantity of Money and other Essays. London: Macmillan, 1969.

FRIEDMAN, Milton. The Social Responsibility of Business is to Increase Its Profits. The New York Times Magazine, 13-09-1970.

GARIBO, A. P. From the Errors of Colonialism to Horrors of War. In: BALLESTEROS, Jesús; FERNÁNDEZ RUIZ-GÁLVEZ, Encarnación; TALAVERA, Pedro (ed.). Globalization and Human rights: Challenges and Answers from a European Perspective. Dordrecht / Heidelberg / London / New York: Springer, 2012. p. 113-141.

GIDE, André. Los alimentos terrestres. Madrid: Alianza Editorial, 1980.

GONZÁLEZ, J. I. La volatilidad acentúa la vulnerabilidad. Innovar: Revista de Ciencias Administrativas y Sociales, n. 021, Bogotá, Universidad Nacional de Colombia, p. 25-30, enero-junio 2003.

GOUX, J. J. La frivolitè de la valeur. Paris: Blusson, 2000.

GOUX, J. J. L'art et l'argent: La rupture moderniste, 1860-1920. Paris: Blusson, 2011.

HARDIN, G. The tragedy of commons. Science, $13 \mathrm{dez} 1968$.

HUERTA DE SOTO, J. Dinero, crédito bancario y ciclos económicos. Madrid: Unión Editorial, 1998.

INTERNATIONAL MONETARY FUND. The Chicago Plan Revisited. IMF Working Paper (Research Department). Prepared by Jaromir Benes and Michael Kumhof; authorized for distribution by Douglas Laxton, August 2012. 
JEVONS, Stanley. Teoría de la economía política. Madrid: Pirámide, 1998.

JONAS, Hans. El principio de responsabilidad: ensayo de una ética para la civilización tecnológica. Barcelona, Herder, 1995.

LIAW, K. Thomas. The business of the Investment Bank: a comprehensive overview. $3^{\text {rd }}$ ed. Hoboken, New Jersey: John Wiley \& Sons, 1999.

MARCEL, Gabriel. Être et avoir. Paris: Aubier, 1935.

MINSKY, Hyman P. Securitization (1987). Preface and Afterword by L. Randall Wray. Policy Note 2008/2. The Levy Economics Institute of Bard College, 2008.

MOFFA, Claudio. Stato sociale, crisi finanziaria, sovranità nazionale: il nodo della Banca centrale Europea. In: GARGULLO, P.; CICARELLI, A. (org.). La dimensione sociale dell'Unione Europea alla prova della crisis globale. Milão: Franco Agnelli, 2012.

NADAL, A. Globalización financiera: las primeras 72 horas. México: La Jornada, 2012.

ORLEAN, A. De l'euphorie à la panique: comment penser la crise financière. Paris: Ed. Rue d'Ulm, 2009.

OST, François. Naturaleza y derecho. Bilbao: Mensajero, 1996

OSTRY, Jonathan D. et alii. Capital Inflow: The Rol of Controls. In: IMF Staff Position Note. 19-022010.

QUIROGA MARTINEZ, R. Participación, supresión de la pobreza y desarrollo sustentable. Santiago de Chile: FOSIS / FDLA, 2000.

RAJAN, Raghuran G. Grietas del sistema: ¿Por qué la economía mundial sigue amenazada?. Bilbao: Deusto, 2011.

RODRIK, Dani. The Globalization Paradox. London - New York: Norton and Co., 2011.

RÖPKE, Wilhelm. Civitas Humana: Cuestiones fundamentales en la reforma de la sociedad y de la economía. Madrid: Revista de Occidente, 1949.

ROUBINI, Nouriel; MIHM, Stephen. Crisis Economics: A crash course in the future of the finance. Londres: Penguin, 2010.

SCHOPENHAUER, Arthur. Parerga y paralipomena: Escritos filosóficos sobre diversos temas. Madrid: Trotta, 2006.

SCHUMACHER F. Small is beautiful: Economics as if people mattered. London: Blond and Briggs, 1973.

SCREPANTI, E.; ZAMAGNI, Stefano. Panorama de historia del pensamiento económico. Barcelona: Ariel, 1997. 
SEN, Amartya. La idea de justicia. Madrid: Taurus, 2009.

SEN, Amartya. Sobre ética y economía. Madrid: Alianza, 1989.

SIMMEL, Georg. Filosofía del Dinero. Granada: Comares, 2003.

STIGLITZ, J. Caída libre: El libre mercado y el hundimiento de la economía mundial. Madrid: Taurus, 2010.

VEBLEN, Thorstein. The Instinct of Workmanship and the Irksomeness of Labor. The American Journal of Sociology, v. 4, 1898-1899, p. 187-201.

WALRAS, Léon. Elementos de economía política pura. Madrid: Alianza, 1987.

ZAMAGNI, Stefano. Dalla teoria del valore utilità alla teoria del valore scelta: le dificoltà della posizione soggettivista in economia politica. Teoria politica, p. 53-67, 1987

ZAMAGNI, Stefano. Marginalismo. In: Enciclopedia delle Scienze sociale. Trecanni, 1996.

Recebido em: 20/02/2017

Aceito em: 20/02/2017 